\title{
Team Building Evolved Through Group Discussion
}

\author{
P.Rajeswari, J.Sasidharan
}

\begin{abstract}
Group Discussion is an important means to share one's opinion, ideas and perspectives on the specified topic or an issue. It generally aims at understanding and analyzing the topic in order to get clear solution for an issue. It promotes team work, cooperation and coordination among the participants. It creates an environment where all the participants share their point of view on the specified topic which leads to a healthy and efficient environment among the team members. It also generates diversity of thought, creativity and team spirit among the members. Team building is something which connects everyone to work together effectively with cooperation of team members and also strengthen collaboration, enlarges knowledge sharing and communication. Everyone gets responsibility to share innovative ideas which would emerge more effectively and efficiently from the members. Team members are able to create a friendly atmosphere which permits everyone to speak confidently. It increases one's motivation, creativity, improved communication and more. This is very constructive at workplace, companies, project discussions, schools, and in any other institutes or departments to conclude a perfect decision or a solution for the problems in their projects. A teamwork environment builds up unity, trust, support and cooperation which facilitate them to attain their goals and objectives.
\end{abstract}

Keywords: efficiency, team spirit, supportiveness, encouragement, creativity

\section{INTRODUCTION}

Group discussion is the form of sharing one's thoughts, ideas, knowledge and opinion through oral communication among the group of members in which the mode of transmission occur mostly in official language. It is an important activity in interviews, academics, and other interactive sessions. And moreover it is the tool to assess the individual's potential during job interview for selecting a suitable person for the concerned profession. In this, nearly 10 to 15 members are expected to participate for sharing their opinions and perspectives on the given topic. Group Discussion plays a vital role to generate more ideas on the topic and to arrive a solution for the issue. It is helpful to get clear idea on the topic and also paves way to solve the problem and for decision making. In most of the organizations, it is conducted to take a better solution for the problem. On getting different perspectives or opinion on a topic, this tool facilitates them to analyze the topic or an issue in a better manner. Group Discussion skill is essential for professional students in order to get selected during interview and also to take part in official meetings. In interview, it is conducted to evaluate the candidate's confidence,

Revised Manuscript Received on May 15, 2020.

* Correspondence Author

Ms.P.Rajeswari*, Assistant Professor, Department of English, Sri Manakula Vinayagar Engineering College, Puducherry, India

SasidharanJayabalan, Stream of Computer Science and Engineering at SriManakula Vinayagar Engineering College, Puducherry, India

(C) The Authors. Published by Blue Eyes Intelligence Engineering and Sciences Publication (BEIESP). This is an open access article under the CC BY-NC-ND license (http://creativecommons.org/licenses/by-nc-nd/4.0/)
Communication skill, and positive approach on the topic, objectivity, creative thinking, active listening, and leadership skill and team work. Candidates who possess above skill would clear the GD round and could attend other rounds in order to get through the interview panel.

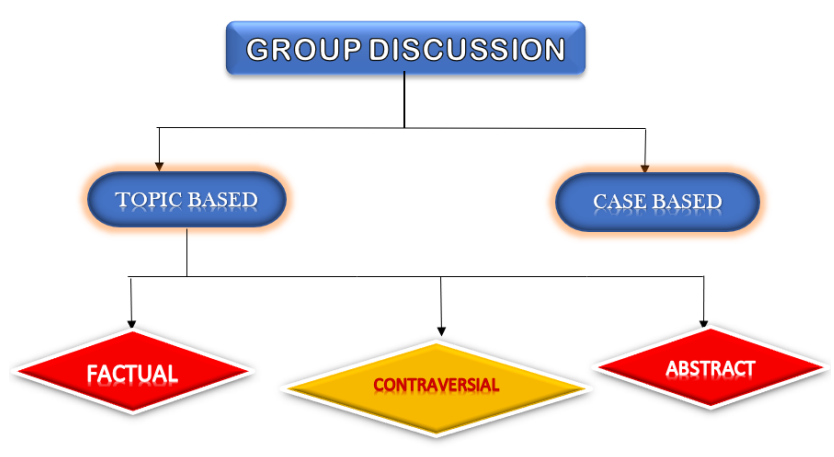

Fig.1 Types of Group Discussion

\section{II.TYPES OF GROUP DISCUSSION}

Group Discussion can be classified as,

- Topic based discussion and

- Case based discussion

Generally group discussion is conducted in schools and colleges in order to test the students' potentiality and for communicative skill. In first case, topic based discussion; topic is given to the participants and allotted time for them to discuss and to arrive at a solution for the topic or problem. The topic may be a general, or a statement or an issue. The participants should discuss only about the topic and should share their perspectives on it and at last end up the session with a proper conclusion. To participate in this, they should be aware of current affair, economics, and politics, sports, or about the recent issue. All the participants should share actual statistics about the topic with some supporting sentence. At the end of the discussion, one must recall all the important points which is analyzed during the session and should arrive at a consensus on the topic or an issue.

\section{A. FACTUAL DISCUSSION}

Factual discussion can be of the day to day occurring of the life or environment around us. It is something in which the participants are aware of the things happening around them every day. It is very easier for them to converse as it is familiar and uncomplicated.

\section{B. CONTROVERSIAL DISCUSSION}

Controversial discussions are the topics discussed which are argumentative. These topics are used to check the temper of the candidates and how do they react to the situations without emotionally and personally.

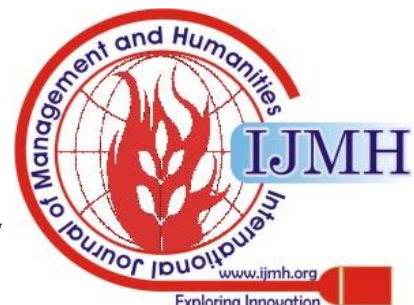


These may also include political topics. It is conducted to analyze the topic on perspectives, the positive and the negative side. The participants should support their topic by providing some examples to it.

\section{ABSTRACT DISCUSSION}

Abstract discussion includes abstract topics which does not need any formal knowledge. It is mostly based on the general knowledge about the topic in which the candidate has to explain his own thoughts. It is generally conducted to test the lateral thinking and creativity of the participants.

\section{CASE BASED DISCUSSION}

Case based discussion is based on the real-life situation. Some real or imaginary situation is given to the candidates in whom they have to discuss with the group members in order to get the solution for the problem. Here, no one would say that your point is incorrect or it is perfect. After analyzing about the situation, getting solution from many angles is encouraged.

\section{III.PURPOSE OF GROUP DISCUSSION}

1. Inventing new ideas

2. Group management

3. Leadership skills

4. Team work

5. Resolution of problems

6. Improving behavioral skills

7. Sharing of thoughts

8. Suggestion for the improvement of the idea

9. Decision making

10. Selection process

\section{IV.METHODOLOGY}

An effective group discussion must follow the basic elements in order to get successful decision:

$>$ All members should speak freely without any hesitation in order to achieve their goal

$>$ Members should stick on to the topic and there is no deviation from their side

$>$ Everyone should listen to each other's opinion to understand the topic clearly

$>$ Presence of mind is essential to put forth their ideas sharply and clearly

$>$ A variety of ideas are gathered so that it can be analyzed properly

$>$ Everyone should take equal chance and no one should dominate

$>$ Everyone should have an agreement and should understand that the team members are working together to make a better decision, or to sort down the problems, or come to a conclusion which leads to further decision

$>$ Use proper gestures i.e. body position must be open and approachable, smile when it required

$>$ All the ideas which is shared must be appropriate to the topic, and deviations are avoided

$>$ Leadership skill is essential for the members which make the discussion very effective

$>$ Cooperation and friendly atmosphere is required to share their ideas and opinions
$>$ Each one's contribution is essential to get different perspectives on a topic in order to arrive a proper solution

$>$ Attentive listening facilitates the members for better analysis and to attain the goal

$>$ Reluctant participant must be encouraged to open up his/her mind.

$>$ Conducive environment must be created so that it paves way for them for their equal contribution

$>$ Team coordination is essential to accomplish the group goal

\section{V.GROUP DISCUSSION STEPS/ PROCESS}

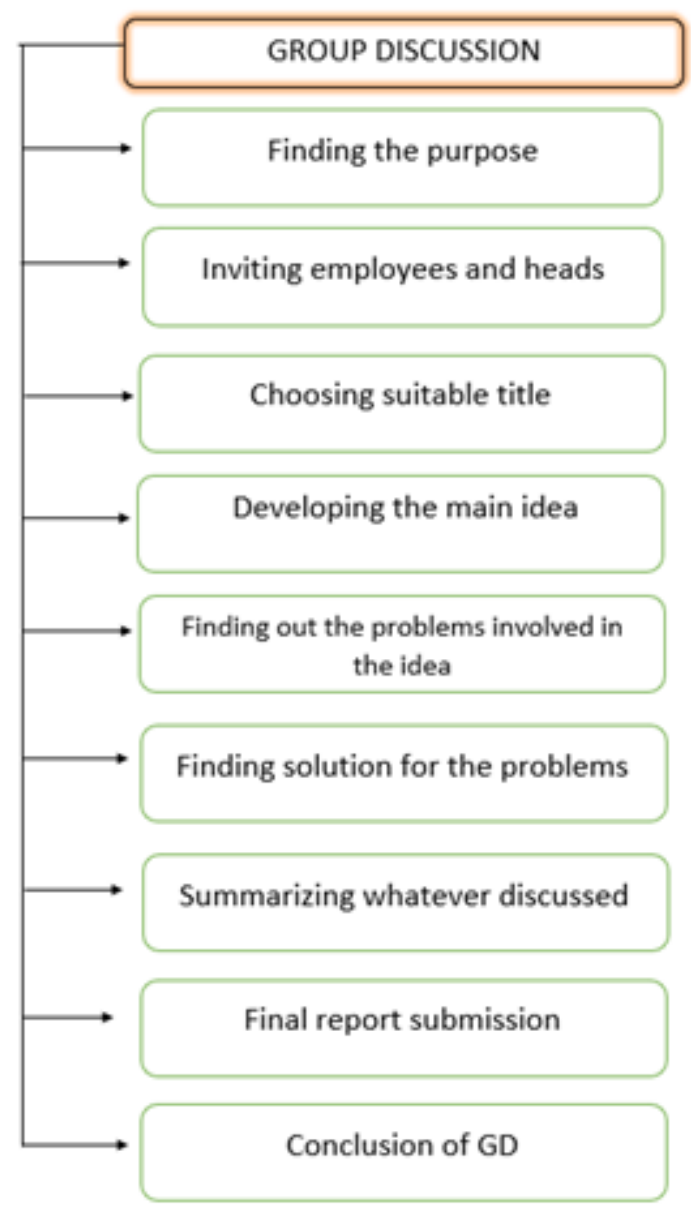

Fig.2 Steps for Group Discussion

\section{VI.GROUP DISCUSSION: EVALUATION PARAMETER}

For effective participation, candidates must be aware of general concepts, knowledge on current issues, politics, social, sports, economics and the basis of technical concepts. Some parameters which are strictly followed to evaluate the person's ability are discussed below.

* Knowledge on the topic: Panel members check the candidates approach on the topic, their depth analysis on the concept, boldness, and their positive approach towards the topic.

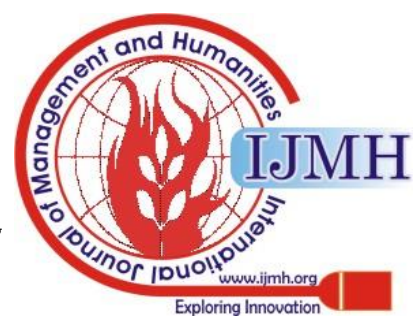


* Communication skills: If the candidates have good proficiency to express their opinions freely, they can impress or convince all the team members through their strong ideas and confidence.

* Team work: In Group discussion, team work is so essential in order to achieve their target. Everyone's cooperation and coordination makes them to work with conducive environment will help them to accomplish their group goal.

* Leadership skills: Everyone in the team must have leadership qualities. There is no elected leader in group discussion. Everyone must think that they are the leader for their group so that they will carry out with proper involvement and cooperation.

* Confidence: Candidates presence of mind and confidence will also encourage other to contribute. It will help them to reach to the great extend. It shows the candidate's good attitude, their persuasiveness and negotiation skill.

* Creativity: Candidates creative thinking shows of ideas which is different from others. It helps them to understand the situation in a better manner and their way of handling the situation also differs.

* Active listening: Participants should listen to each other's opinion in order to get idea and also to understand the topic better. It helps them to be a good speaker and can put forth their ideas freely.

\section{VII.TEAM BUILDING}

Team building is the method of improving the team skills to work together in an arranged manner to get out the success of the project or any work assigned to them. Team work is the main prompt of team building where the people of the team can improve their strength and weaknesses to overcome the barriers in their project. This is where the team building skills can be evolved through group discussions.

Team building may be classified into five stages:
1. FORMING
2. STORMING
3. NORMING
4. PERFORMING
5. ADJOURNING

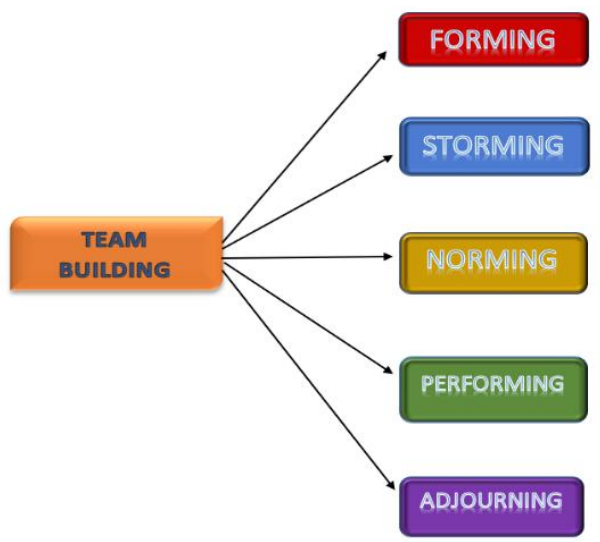

Fig.3 Stages of Team Building their uniqueness and their potentiality and the value

\section{A. FORMING:}

This stage of team building is quite confusing to the team members as they don't know what the theme of the session is. Some may be anxious about what they are going to do, and some may not have any idea about it. In this stage, the main involvement goes to the team leader, because he is the person one who has to explain about the project or the work they have to do. So, it may take some time for the team members to understand and to fully involve in the idea of the team leader.

\section{B. STORMING:}

This stage may create conflicts between the team members and that's how most of the people fail in this phase because of the individual's ideas of individual team members. Mostly, the ideas may vary from person to person which is the cause for the conflict evolved. This can be solved by being positive and creating relationship between themselves and accepting all the opinions and to correctly choose which would suit the project to bring it out with success

\section{NORMING:}

Norming is also known as 'Team Building' where the team starts to understand each other's opinion where everyone starts to appreciate others and we can see the involvement of the members and the progress of the team increases gradually. The team members help each other which resolve most of the problems and increase the strength of the team. Though the stages of storming and norming may vary a lot, and that's how the team work helps in reducing conflicts and increases the relationship between members to step forward the project with good progress in it.

\section{PERFORMING:}

Performing stage involves more hard work and involvement to make the project succeed. In this stage, team leader has a great role of improving the team members. The task is not only to focus on the project and also to improve other areas of interest and work which can pave way for the successful performance of the project. It helps them to work with team spirit and achieve their target in a successful manner. This stage concentrates more on the achievement and target of the project.

\section{E. ADJOURNING:}

This is a wonderful stage where the team members start to celebrate or enjoy the achievement of their team where the project work came out with success. This phase is not only for the enjoyment purpose, but also to encourage the team and their members to work harder in their upcoming projects to succeed it in a grand manner.

\section{WHY TEAM BUILDING?}

Team building is something very important and it is the essential factor to start out any of the project or the task. Whatever may be assigned to you, without a better team work, one cannot succeed in their effort.

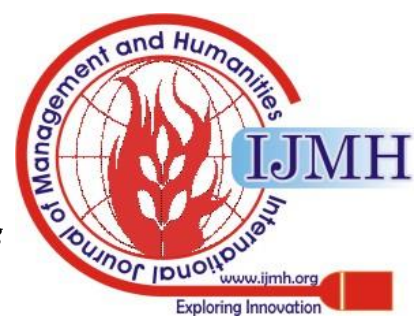


So a good team work, an encouraging team leader and a powerful start may be the things which are very important to start up your effort to finish it in a successful manner. Hence, team building plays a great role in this.

\section{IX.THINGS TO REMEMBER!}

1. Make your mind to accept your colleague's opinion

2. Be active

3. Listen to everyone's point

4. Give your opinion in a positive manner

5. Obey team leader's order

6. Follow the rules given to you

7. Support for other's opinion if necessary

8. Finally, build your own team to make your project success.

\section{X.TEAM BUILDING EVOLVED FROM GROUP DISCUSSION -- AN ANALYSIS AND CONCLUSION}

Team building is something which can mostly be evolved through group discussion. Group discussion is something which can be compared to meeting or discussion where all gathered as a group (also termed a team) to furnish out their opinion. One has to realize that group discussion is the main important thing which happens in a formal manner to invite innovative ideas from all the participants. It is the platform for all the participants where everyone is given equal opportunity to open up their mind for improving the progress to the next stage. Here, no member's opinions are compared, rather everyone's ideas are appreciated, whether correct or wrong, so that everyone can learn new things and it also paves way for the creation of the new idea.

Group discussion is done in schools, colleges, club activities, and mainly in the workplace and corporation. It follows the hierarchical order; first the head of the companies have their discussion with other work heads. Now, these each head have their discussion with the team leaders under them. After that, each team leader has discussion with their team members. This is the order followed in every organization. Now, this order is followed in a reverse manner. That is, each opinion of each team member to team leader, team leader to all the other leaders, then all team leaders to their heads, all heads to their company head. As discussed earlier, the five important steps of team building: forming, storming, norming, performing and adjourning, these stages are very important for any group to build their team work. When a group discussion is conducted, everyone should follow these stages so that it can assist them to lead their way towards success. When success is achieved, it is mainly due to their team's effort. It makes them healthier in case of knowledge sharing and also to improve their language skills indirectly. It helps them to achieve proper suggestion which paves way to achieve their success. Neither silence, nor individual discussion is going to help them, but group discussion is the only key to reach the feat. Hence, team building strengthens accountability and can help to make effective decisions quicker. It reduces the individual's pressure on completing the task and ensures productivity and job satisfaction at the end of the task.

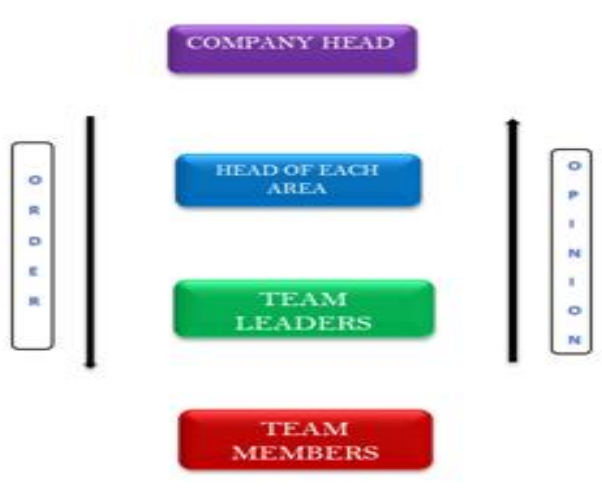

Fig.4 Order of Group Discussion

\section{REFERENCES}

1. Bhatnagar, Nitin \&Mamta Bhatnagar. "Communicative English forEngineers and Professionals", New Delhi: Dorling Kindersley Pvt. Ltd., 2010.

2. Geetanjali, "What is Group Discussion? https://www.naukri.com/blog/what-is-group-discussion/, March 20, 2020.

3. McNamara, Carter. "How to Build Highly Effective Team?", https://managementhelp.org/groups/team-building.htm , March 21, 2020

4. Rizvi, Ashraf M. "Effective Technical Communication", New Delhi: Mc-Graw Hill Education Pvt. Ltd., 2006.

5. Team Building, https://www.tbae.co.za/team-building.htm, March 22, 2020.

6. Teamwork Skills: Being an effective group member, https://uwaterloo.ca/centre-for-teaching-excellence/teachingresources/teaching-tips/tips-students/being-partteam/teamwork-skills-being-effective-group-member, April 5, 2020.

7. "Types of Group Discussion", http://placement.freshersworld.com/types-of-gd/33121969 , March 21, 2020.

8. Types of Group Discussion, https:/q4interview.com/groupdiscussion- types-and-evaluation-criteria.php., April 18, 2020.

\section{AUTHOR PROFILE}

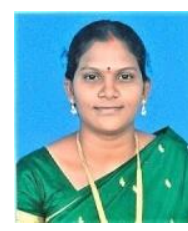

Ms.P.Rajeswari, working as an Assistant Professor in the Department of English for the past five years at Sri ManakulaVinayagar Engineering College, Puducherry. Also, she is doing her Part-time Ph.D (English Literature) in BharathiarUniversity. She is having more than ten years of experience in Engineering Colleges. Her specialization is Indian Literature in English, Diaspora Literature, and Comparative studies. She has presented more than ten papers in International Conference, Seminar etc.

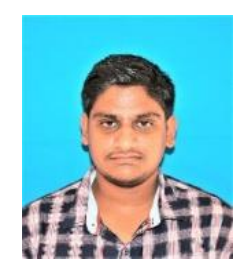

Sasidharan Jayabalan, pursuing B.Tech in the stream of Computer Science and Engineering at SriManakulaVinayagar Engineering College, Puducherry. He is much interested in Aerospace and his goal is to join in Indian Space Research Organisation in future. At present, he is doing project in CubeSat which is based on weather meteorological balloon.

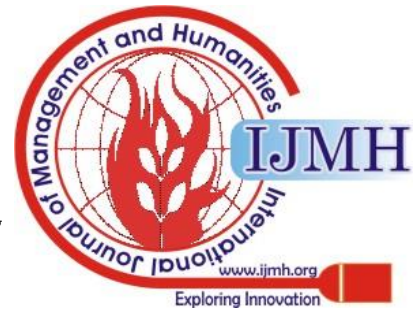

